\title{
La humildad según Leonardo Polo
}

\section{Humility according to Leonardo Polo}

\author{
JUAN FERNANDO SELLÉS DAUDER \\ UNIVERSIDAD DE NAVARRA
}

Recibido: 06/11/2019 Aceptado:16/12/2019

\section{RESUMEN}

En este trabajo se estudia la humidad según L. Polo. Se sostiene que no es una virtud de la voluntad, sino una característica de la libertad personal. La voluntad pertenece a la esencia del hombre; en cambio, la libertad personal es una dimensión del acto de ser personal humano.

$$
\text { PALABRAS CLAVE }
$$

HUMILDAD, L. POLO, VIRTUD, VOLUNTAD, ESENTIA HOMINIS, LIBERTAD PERSONAL, ACTUS ESSENDI HOMINIS.

\begin{abstract}
In this paper we study the humility according L. Polo. We defend that humility is not a virtue of the will, but a characteristic of personal freedom. The will belongs to human essence; meanwhile, the personal freedom is a dimension of the personal act of been.

KEYWORDS

HUMILITY, L. POLO, VIRTUE, WILL, HUMAN ESSENCE, PERSONAL FREEDOM, PERSONAL ACT OF BEEN.
\end{abstract}

\section{LA HUMILDAD DEL CONOCER HUMANO}

ANTES DE ATENDER A LA HUMILDAD PERSONAL, reparemos en una realidad humana que no puede ser sino humilde: el conocer. Polo predica la humidad 
del acto de conocer, el cual al pensar forma un objeto pensado; en tal formación el acto se limita a presentar el objeto sin presentarse jamás él mismo:

El acto de pensar es sumamente discreto; pensar es respetar. Para pensar un contenido es menester que el acto de pensar se oculte; si no se oculta, es imposible conocer un contenido. Dicha discreción se describe estrictamente así: la presencia es el ocultamiento que se oculta... El pensamiento, de suyo, no es soberbio, sino enteramente humilde porque actúa a favor de. La presencia abre lo abierto y eso es un beneficio... Si la presencia no se ocultara, no podría ser la presencia de lo abierto, sino que se haría vanamente presente. La presencia no se presenta, sino que se oculta. ${ }^{1}$

La presencia mental presenta lo presentado, pero no se presenta. El acto de conocer un objeto pensado (i.e. 'perro') se limita a presentarlo. Si se presentase a sí mismo, en la medida en que lo hiciese, no presentaría el objeto pensado y, además, no podríamos distinguirlo de él. Pero es claro que un acto de pensar es una realidad concreta, mientras que una forma pensada es de orden ideal y universal. Por eso la teoría reflexiva de la verdad, es decir, esa opinión que sostiene que un acto de conocer se conoce a sí mismo a la par que conoce el objeto conocido es, sin más, un sinsentido ${ }^{2}$. Pues bien, del mismo modo que todo conocer humano no se presenta sino que se oculta, lo mismo cabe decir de la humildad ${ }^{3}$.

La aludida teoría reflexiva de la verdad es un desliz que no advierte que el conocer humano es siempre distinto de lo conocido, el método noético del tema sabido. Polo escribe: «Que el ver no sea lo visto significa que es transpa-

1 POLO, L. 2016: Curso de teoría del conocimiento, vol. II, en Obras Completas, Serie A, vol., V. Pamplona: Eunsa, p. 107.

2 Esta teoría actual sigue dos tradiciones: la fenomenológica y la neotomista. La primera porque Brentano, al leer a Aristóteles, consideró que lo intencional en el conocer es el acto, la operación inmanente, en vez del objeto conocido, y esa tesis la transmitió a Husserl y a Meinong, y el padre de la fenomenología la transfirió a Heidegger, Scheler, etc. Cf. sobre esto mi trabajo: «Revisión poliana de la fenomenología husserliana», Estudios Filosóficos Polianos, 2 (2015) 24-42. La segunda, porque basándose en 2 textos De Veritate de Tomás de Aquino algunos tomistas del s. XX (Boyer, De Finance, Derisi, Fabro, Cardona, Millán-Puelles, etc.) y otros autores más recientes (A. Llano, C. Segura, Sainte-Marie, Toribio, etc.) consideran que todo acto de conocer es auto-intencional; es más, algunos de ellos admiten que el acto tiene una doble, triple cuádruple... intencionalidad. Cf. sobre esto mi trabajo: «Revisión de la teoría reflexiva del conocer humano», Sapientia, LXIX/233 (2013) pp. 67-95.

3 «La humildad es una virtud humilde... Quien se jactara de poseerla mostraría simplemente que no la tiene». COMTE-SPONVILLE, A. 1995: Pequeño tratado de las grandes virtudes, Barcelona, Buenos Aires, México D.F., Santiago de Chile: ed. Andrés Bello, p. 143. «La humildad es una virtud que apenas llama la atención», en LUCA DE TENA, F. 2007: La humildad explicada. Madrid: Palabra, p. 9. 
rente, es transparencia. ¿Y la transparencia que es? La luz tomada como luz. ¿Y esto que quiere decir? Que es humildad, que se ignora; pero esa ignorancia sería en todo caso una docta ignorancia» ${ }^{4}$. La raíz de dicho lapsus reside en admitir injustificadamente que todos los actos de conocer son iguales y del mismo nivel. Pero una cosa es conocer un objeto pensado y otra muy distinta conocer un acto de conocer, pues el objeto pensado no se puede conocer sino abstrayéndolo de la realidad física, mientras que al acto de pensar no hay quien lo abstraiga, sencillamente porque es inmaterial. Por eso, para conocer un acto de conocer se requiere de otro superior a él, y «la iluminación de la presencia mental en su ocultamiento no desmiente la humildad de su ocultamiento» ${ }^{5}$.

Si a lo que precede se objeta que con esta tesis se abre un proceso al infinito, es decir, que al acto que conoce un acto debe conocerlo otro acto y así sucesivamente, a esta objeción hay que responder que el «acto» de conocer que conoce una operación inmanente es un «hábito adquirido» ${ }^{6}$-noción práctimente olvidada en teoría del conocimiento desde el s. XIV hasta la fecha-, y que un hábito adquirido es una perfección de la facultad -la inteligencia-el cual, por equivaler al crecimiento perfectivo de esta potencia, no se puede conocer ni por una operación inmanente ni por otro hábito adquirido, sino por un «hábito innato»-precisamente ese descubierto por San Jerónimo en el s. IV, y asimismo olvidado desde el s. XIV hasta hoy-: la sindéresis ${ }^{7}$. Para quien tenga una fijación con la hipótesis del proceso al infinito y siga preguntando con qué se conoce un hábito innato, la respuesta apela a la realidad cognoscitiva humana superior, la descubierta por Aristóteles en el s. IV a. C. -y, salvo excepción, mal interpretada desde él hasta hoy-: «el intelecto agente» ${ }^{8}$, que equivale al conocer personal o conocer a nivel de acto de ser humano, el cual, obviamente, tampoco se puede tener a sí mismo como tema.

4 POLO, L. 2018: «La persona humana como ser cognoscente», en Escritos Menores (2001-2014), en Obras Completas, Serie A, vol., XXVI, Pamplona: Eunsa, p. 94.

5 POLO, L. 2016: Curso de teoría del conocimiento, vol. III, en Obras Completas, Serie A, vol., VI, Pamplona: Eunsa, p. 36.

6 Cf. mis trabajos: «Los hábitos intelectuales según Leonardo Polo», Anuario Filosófico, XXIX/2 (1996) pp. 1017-1036; «¿Es posible conocer la verdad? Propuesta: el conocimiento por hábitos», Logos. Anales del Seminario de Metafísica, 41 (2008) pp. 187-202.

7 Cf. MOlinA, La sindéresis, Cuadernos de Anuario Filosófico, Serie Universitaria, $\mathrm{n}^{\circ}$ 82, Servicio de Publicaciones de la Universidad de Navarra, Pamplona, 1999. Cf. asimismo mi trabajo: «La sindéresis o razón natural como la apertura cognoscitiva de la persona humana a su propia naturaleza. Una propuesta desde Tomás de Aquino», Revista Española de Filosofía Medieval, 10 (2003) pp. 321-333.

8 Cf. mi tripartito trabajo: (2012) El intelecto agente y los filósofos. Venturas y desventuras del supremo hallazgo aristotélico sobre el hombre (I), ss. IV a. C. - XV, Pamplona: Eunsa; (II), ss. XVI-XVII, 2017; (III), ss. XVIII-XXI, 2017. 
Las operaciones inmanentes de la inteligencia son actos, los hábitos adquiridos son actos, los hábitos innatos son actos y el intelecto agente es el acto de los actos cognoscitivos humanos, y ninguno de los actos de conocer se conoce a sí mismo, lo cual indica que el conocer humano no puede ser soberbio a ningún nivel sino siempre humilde. El superior de ellos, el intelecto agente, es personal, y la persona nativamente no es soberbia, porque es pura apertura dependiente del Creador. Por eso todo otro acto de conocer, desde el mínimo racional, el que se agota presentando un objeto conocido, es una manifestación del acto de ser personal y, por ende, muestra la humildad personal: «por eso conocer es indicio de la persona; persona significa darse. Es nota de la persona ser generosa. A veces se dice que la generosidad es cosa de la voluntad, pero la generosidad es intrínseca al acto de conocer» ${ }^{9}$.

Con lo indicado se ve de modo claro cuál es la índole de la humildad. Por una parte, el completo «olvido de sí», pues todo acto de conocer se agota iluminando lo otro; y por otra, precisamente esto: el «jugar por entero a favor de lo otro», pues lo que ilumina un acto es siempre distinto de sí. En efecto, la mayor parte de ellos -los de la esencia del hombre- miran a lo inferior ${ }^{10}$; y la minoría -los del acto de ser personal humano- a lo superior, pero ninguno se mira a sí. Pues bien, si el conocimiento humano no es soberbio a ningún nivel, ¿de donde surge en el hombre el superior de los vicios: la soberbia? Según Polo «la soberbia es un vicio subjetivo» ${ }^{11}$, es decir, la soberbia nace del sujeto, pero no del conocer personal, sino de la libertad personal: «he señalado repetidas veces que el conocimiento es humilde; no hay soberbia intelectual.

9 POLO, L., Curso de teoría del conocimiento, vol. II, ed. cit., p. 107.

10 «La noción de potencia pasiva señala la humildad de la vida valorante, es decir, del refuerzo vital. De aquí, que la inteligencia y la voluntad empiecen a operar en determinada edad. La unión del alma con el cuerpo se entiende como inspiración valorativa; el alma es vida añadida». POLO, L. 2015: Antropología trascendental, vol. II, en Obras Completas, Serie A, vol. XV. Pamplona: Eunsa, p. 286. Tal activación y valoración se lleva a cabo desde la sindéresis, que es el ápice de la esencia del hombre. Por eso Polo escribe que «la suscitación es propia del ápice de la iluminación esencial. La ausencia de esfuerzo de dicha luz intelectual estriba en su humildad: inventa lo inferior. Aunque la iluminación esencial es libre y, por tanto, lo suscitado una novedad, sería ridículo que ello fuera motivo de engreimiento, ya que la iluminación suscitante es creada». Ibid., p. 336.

Los conocedores de la filosofía de L. Polo saben que, según él, la sindéresis tiene dos miembros, uno inferior -el ver-yo-, que ilumina la razón, y otro superior -el querer-yo-, que ilumina la voluntad. Pues bien, de ambos cabe predicar la humildad. Del primero Polo lo dice explícitamente: «Ver-yo es humilde también por no ser reflexivo, por jugar a favor, y por depender de la luz personal cuya búsqueda omite.» Ibid., p. 336, nota 61. Y del segundo indica: «la humildad ilumina que el poder voluntario tiene tope y que sólo así es posible la intersubjetividad». Ibid., p. 526, nota 312.

11 POLO, L., Curso de teoría del conocimiento, vol. II, ed. cit., p. 106. 
Hay soberbios intelectuales, pero la inteligencia no es soberbia. El hombre puede ser soberbio, pero la inteligencia no» ${ }^{12}$. Esto, en rigor, es indicativo de que todo conocer humano procede de Dios, y que donde radica el mal es en el engreimiento subjetivo respecto de lo que uno conoce ${ }^{13}$.

\section{LA HUMILDAD AL MARGEN DE LA REVELACIÓN DIVINA}

La humildad es tenida en gran valor en la revelación judeocristiana, tanto en el Antiguo $^{14}$ como en el Nuevo Testamento ${ }^{15}$. Obviamente, de este último testamente se han hecho eco muchos autores cristianos ${ }^{16}$. Pero también y desde tiempo inmemorial del primero, de entre los cuales Polo suele mencionar a uno de los medievales, Maimónides:

Según Aristóteles, las virtudes residen en el término medio. Maimónides alega que para algunas virtudes no hay término medio. Un ejemplo es la humildad: nunca se es suficientemente humilde. La humildad viene a ser la actitud virtuosa humana en orden a Dios, o sea, lo que en la moral se acerca más a lo trascendenta ${ }^{17}$,

Es decir, lo que en el plano de la esencia del hombre se acerca más al nivel del acto de ser personal humano.

Nótese que en el texto anterior, perteneciente a su gran obra antropológica, publicada por primera vez en 1999, Polo dice que la humildad es una virtud moral, de modo que pertenecería a la «esencia» del hombre. Sin embargo, en una obra posterior cuya primera edición es de 2014 -publicada por tanto 15 años después de aquélla-, y con la misma referencia al pensador medieval judío Polo escribe: «Al aceptarse uno como es -como persona- se da cuenta

12 POLO, L. 2015: El conocimiento del universo físico, en Obras Completas, Serie A, vol. XX. Pamplona: Eunsa, p. 38.

13 Una manifestación práctica de tal vanidad es no dar a conocer lo que se sabe. Por eso Polo acostumbraba a decir que «las ideas están mejor en cuatro cabezas que no en una». Recuérdese, a título de ejemplo, que el pecado del ángel caído fue la soberbia, que Polo concretaba de este modo: «Dios (el superior tema conocido) solo para mí: exclusividad»: «La peor intemperancia es la soberbia porque es querer hacer propio un bien espiritual (pecado angelical)». POLO, L., La articulación de lo público y lo privado, PAD, Lima (Perú) 1-IX-1986, pro-manuscripto, p. 15. «Es un pecado de soberbia como el del ángel caído el intentar tener una relación sólo con Dios». Conversaciones en Torreblanca (Colombia), 25-30-VI-1997, pro-manuscripto, p. 105.

14 «Donde hay humildad, habrá sabiduría» Prov. XI, 9.

15 «Aprended de mi que soy manso y humilde de corazón». Mt., XI, 29.

16 Cf. por ejemplo: CASTRO, J. 2006: La sabiduría de la humildad. Madrid: San Pablo; CHIESA, P.J.M. 2007: Amor, soberbia y humildad.Tucumás: ed. del autor.

17 POLO, L. 2015: Antropología trascendental, vol. I, en Obras Completas, Serie A, vol. XV. Pamplona: Eunsa, p. 258. 
de que depende de Dios -todo lo ha recibido de Él-. De ahí nace la humildad, que no es una virtud griega. Además, antes que una virtud, es una aceptación del propio ser. Por eso, según el decir de Maimónides, la humildad carece de punto medio: nunca se es suficientemente humilde» ${ }^{18}$, lo cual parece denotar que hay que colocarla en el plano trascendental del acto de ser personal humano. De modo que tenemos una oposición temática entre dos textos polianos.

Con todo, el último texto procede de un inédito poliano de $1963^{19}$. Y asimismo, contamos con otro inédito del año 1989 de contenido similar ${ }^{20}$. La disparidad de contenido de los textos precedentes abren la pregunta decisiva: ¿la humildad es del plano de la esencia del hombre, o pertenece al acto de ser personal? Trataremos de responderla más abajo, pero antes hay que indicar que si la humildad no fue una virtud tenida como tal por la filosofía griega clásica al margen del cristianismo ${ }^{21}$, tampoco es tenida como tal fuera del influjo de la revelación judeocristiana, como advirtió Kierkegaard ${ }^{22}$. El prototipo de

18 POLO, L., Epistemología, creación y divinidad, en Obras Completas, Serie A, vol. XXVII, Pamplona, Eunsa, 2015, p. 201.

19 Cf. POLO, L., «Sobre la libertad». Conferencia pronunciada en el C.M. Belagua de la Universidad de Navarra, Pamplona, 3-II-65, pro-manuscripto, p. 4.

20 «Maimónides... sostiene que (la ética griega) no es toda la ética. El ejemplo con el que ilustra esa tesis es claro. Se trata de un gran valor ético, que puede no parecer filosófico: la humildad. Está en la tradición veterotestamentaria, y naturalmente también vale para un cristiano, porque en el Nuevo Testamento se encuentra todavía más claro. Según Maimónides, la humildad no cabe dentro de la ética griega. A mi modo de ver, San Agustín también rondó esa idea cuando dijo que las virtudes de los paganos - griegos y romanos helenizados precristianos- tenían mucho de vicio; que no eran virtudes redondas o auténticas, justo porque llevan consigo un desconocimiento de la humildad. También para Maimónides la humildad es la actitud más importante en el hombre. Y esta tesis tiene interés precisamente porque se trata de un judío que a la vez sabe filosofía, y se da cuenta de que la humildad no es exactamente un asunto de ética filosófica». POLO, L., «Acto y actualidad en Aristóteles». Conferencia pronunciada en la Universidad de La Sabana, Bogotá, 7-IX-1989, pro-manuscripto, p. 6.

21 Esta tesis poliana ya fue advertida por otros autores: «Esta virtud de humildad no la supo enseñar Platón, ni Sócrates, ni Aristóteles». ALONSO RODRÍGUEZ, P. s.f.: La humildad, Madrid: España Editorial, p. 10. «Los gentiles no conocieron de la humildad más que la modestia, y lo que de ella conocieron lo practicaron con bastante imperfección». BEAUDENOM, C. 1944: Formación en la humildad. Barcelona: Eugenio Subirana, p. 15; «La diferencia más notable entre las virtudes cristianas y las paganas está precisamente en la humildad». LORDA, J.L. 2013: Virtudes. Madrid: Rialp, p. 103.

22 «Bueno puede ser cualquiera, pero siempre se requiere talento para ser malo. De ahí que muchos quieran ser filósofos, pero no cristianos, pues para ser filósofo se requiere talento, y para ser cristiano, humildad, algo que cualquiera puede tener si así lo quiere». KIERKEGAARD, S. 1997: O lo uno o lo otro. Un fragmento de vida II. Madrid: Trotta, p. 206. 
esta opinión lo encontramos en la modernidad en Nietzsche. Polo recuerda que pensador de Röcken sostuvo que:

La humildad no es más que un modo de hacerse valer. Aparentemente, el débil excluye de sí la voluntad de poder, y exalta la humildad, pero ésta es una forma disimulada de la voluntad de poder. Ese disimulo es un engaño, un subterfugio, un procedimiento sutil, propio de los débiles: si la humildad es un valor, los más débiles son los más valiosos. La inversión de valores está clara. Por tanto, la humildad no existe como tal y hay que entenderla en estilo indirecto, porque no es más que un enmascaramiento de la voluntad de poder, del que uno tal vez no es consciente, pero que impera por completo en el fondo de la actitud... La humildad y la idea de igualdad son voluntad de poder transformada, descargada del esfuerzo de superación, es decir, formas astutas de subyugar al fuerte. ${ }^{23}$

Polo sostiene que tampoco está bien tratada la humidad en otros pensadores recientes que se ponen a sí mismos al margen del cristianismo, por ejemplo, en Heidegger ${ }^{24}$.

\section{LA HUMILDAD COMO FUNDAMENTO DE TODAS LAS VIRTUDES Y ALGUNAS DE} SUS MANIFESTACIONES

Para Polo «la humildad (es la) virtud sin la cual las demás no lo son, como dijo Cervantes» ${ }^{25}$. Por tanto, es el fundamento de las demás. Pero si las

23 POLO, L. 2016: Nominalismo, idealismo y realismo, en Obras Completas, Serie A, vol., XIV. Pamplona: Eunsa, p. 151. En otro lugar Polo agrega: «A Nietzsche le parece claro que la religión es propia de seres humanos con una voluntad disminuida. Por eso, sobre todo en el cristianismo, la actitud ante Dios es de sometimiento y humildad. Estas pretendidas virtudes, enteramente contrarias a la voluntad de poder, sólo pueden entenderse como enmascaramientos suyos: es imposible que sean sinceras, puesto que entrañan el anonadamiento de la voluntad de poder». (2018): Nietzsche como pensador de dualidades, en Obras Completas, Serie A, vol., XVII. Pamplona: Eunsa, p. 89. «En su crítica al cristianismo Nietzsche entiende que la humildad es un recurso para defenderse de los fuertes». Ibid., p. 222. En otra publicación añade: «La humildad, por ejemplo, dice Nietzsche, es un lazo que el débil tiende al fuerte: somos humildes, caritativos, respetuosos; y eso se le ocurre al que sólo tiene una vitalidad débil, porque al fuerte no se le ocurre establecer un régimen de solidaridad o de igualdad, como hacen los socialistas. Las críticas de Nietzsche se dirigen al cristianismo y al socialismo». El conocimiento del universo físico, ed. cit., p. 259.

24 «Mi discrepancia con la Gelassenheit es que expresa una subordinación excesiva respecto del ser... Sin embargo, la humildad no es una invitación a quedarse mudo ante el ser». POLO, L., Nietzsche como pensador de dualidades, ed. cit., p. 211.

25 POLO, L., Epistemología, creación y divinidad, ed. cit., p. 301. Esto lo reitera en un inédito: «la humildad es importantísima, porque sin esa virtud no lo son las demás... Eso lo dijo un antepasado mío: Cervantes». Conversaciones en Pamplona, 2-III-2015, pro-manuscripto $\mathrm{p}$. 1. El texto cervantino dice así: «la humildad es la base y fundamento de todas las virtudes, que 
virtudes se asientan en la voluntad, su fundamento debe ser superior a esta potencia. Polo también indica que «la humildad está en el orden del fundamento de la vida ${ }^{26}$, y como en nosotros distingue realmente, según inferioridad y superioridad, entre la vida y el viviente, o sea, entre la esencia del hombre y el acto de ser personal ${ }^{27}$, si la humildad es fundamento de la vida debe ser superior a ella, es decir, distintiva del viviente personal ${ }^{28}$.

En cuanto a las manifestaciones de la humildad, éstas son, para Polo, variadas. Yendo de las inferiores a las superiores cabe decir que una de ellas estriba en que el hombre no se mida a sí mismo por sus obras o productos elaborados: «se precisa cierta humildad para aceptar que todo lo que producimos -la cultura, la técnica ¡El Arte! - no es, en su ser, sino medios» ${ }^{29}$. Otra es estar esperanzado ante el fututo laboral, pues el pretender excesivas seguridades es manifestación de soberbia: «es claro que la práctica humana no está definida por una ecuación de equivalencia entre presente y futuro, sino por una curiosa descompensación que obliga a estar más atento y a ser más humilde. En el fondo de la actitud que pide garantías a ultranza, hay soberbia» ${ }^{30}$. Otra manifestación es vivir la virtud de la pureza, porque ésta es «la humildad de la carne, del corazón que no quiere pudrirse» ${ }^{31}$.

Con respecto a los demás, una manifestación de humildad es, obviamente, considerar su dignidad, del mismo nivel que nosotros, pues de lo contrario no les ayudaremos:

La misericordia se ha de manifestar con obras que busquen remediar tanto a las necesidades materiales (dar de comer al hambriento, visitar a los enfermos...)

sin ella no hay alguna que lo sea». CERVANTES, M. 1973:Novelas Ejemplares 1. El coloquio de los perros. Madrid: Emesa, p. 266.

26 POLO, L. 2017: «El concepto de vida en Mñor. Escrivá», en Escritos Menores (19511990), en Obras Completas, Serie A, vol., IX. Pamplona: Eunsa, p. 163, nota 23.

27 «La esencia de la persona humana es... vida esencial de un viviente personal». POLO, L., Epistemología, creación y divinidad, ed. cit., p. 239. Cf. al respecto: CASTILLO, G., «Vivere viventibus est essentia», en Studia Poliana, 3 (2001) pp. 61-71.

28 Por tanto, no parece acertada la descripción kantiana según la cual «la conciencia y el sentimiento de su escaso valor moral en comparación con la ley es la humildad» (KANT, I., Metafísica de las costumbres, segunda sección, art. 16), no sólo porque la humildad no es ningún sentimiento, sino porque la persona está por encima de la ley moral universal, precisamente por eso puedo ratificarla o conculcarla.

29 POLO, L. 2015: La persona humana y su crecimiento, en Obras Completas, Serie A, vol. XIII. Pamplona: Eunsa, p. 122.

30 POLO, L. 2015: Filosofía y economía, en Obras Completas, Serie A, vol. XXV. Pamplona: Eunsa, p. 358.

31 POLO, L., «Reseña sobre el libro Surco», pro-manuscripto, p. 7. 
como a las espirituales (aconsejar, consolar, confortar...). Para tratar de esta manera a los demás se requiere la humildad: no considerarnos superiores a ellos ${ }^{32}$.

Sin embargo, lo contrario es lo usual, por ejemplo, en el mundo educativo, político, laboral, empresarial, etc., ámbitos que están estructurados con una marcada jerarquía en la que se tiende a considerar en poco a los inferiores. Por eso Polo indicaba que:

La acción de gobierno va dirigida a la mejora de los otros agentes, y es recíproca... Por tanto, si el gobernante no es humilde, fracasa. El humanismo es imprescindible en política porque la acción de gobierno se distingue de la acción productiva. La acción de gobierno no consiste en imprimir la propia impronta en los demás, sino en activar sus energías, y esto es profundamente ético: los sistemas libres son sistemas que interactúan; un sistema libre no existe aislado. ${ }^{33}$

\section{LA HUMILDAD Y LOS TRASCENDENTALES PERSONALES}

Leonardo Polo ha descubierto que la coexistencia libre, el conocer y el amor son trascendentales personales, es decir, rasgos del acto de ser personal humano, no propiedades de la esencia del hombre, como pueden ser, por ejemplo, las potencias de la inteligencia y la voluntad. Pues bien, Polo vincula la humildad a las dimensiones trascendentales, los cuales, además de ser referentes al ser divino, son crecientes respecto de él y por él elevables.

En cuanto a la libertad personal Polo afirma que «la libertad creada solo se desarrolla normalmente en un régimen interno de humildad y de obediencia; sin obediencia la libertad personal humana no es fiel a su Creador, y carece de la coherencia que le es propia» ${ }^{34}$. Por lo que se refiere al conocer personal, para su exposición Polo parte de una expresión acuñada por la santa de Ávila: «Santa Teresa decía que la humildad es andar en verdad» ${ }^{35}$. Des-

32 POLO, L., Epistemología, creación y divinidad, ed. cit., p. 303.

33 POLO, L., 2018: Ética: hacia una versión moderna de los temas clásicos, en Obras Completas, Seria A, vol. XI. Pamplona: Eunsa, p. 308.

34 POLO, L., Epistemología, creación y divinidad, ed. cit., p. 225.

35 POLO, L., Curso de teoría del conocimiento, vol. II, ed. cit., p. 106. En otro lugar indica: «La humildad no es sentirse incapaz, sino andar en la verdad, como decía Santa Teresa». Epistemología, creación y divinidad, ed. cit., p. 126. La santa de Ávila escribió: «humildad es andar en verdad». STA. TERESA, Moradas, VI, 10. La tesis teresiana parece tener su origen en Agustín de Hipona: «La humildad habla de la verdad, y la verdad de la humildad; es decir, la humildad, de la verdad de Dios, y la verdad, de la humildad del hombre» SAN AGUSTÍN, Sermón, 183, 4; «toda tu humildad consiste en que te conozcas». Tratado sobre el Evangelio de San Juan, 25, 16. «Si me preguntáis qué es lo más esencial en la religión... os responderé: lo primero la humildad; lo segundo, la humildad; y lo tercero, la humildad». San Agustín, Epístola 118. 
cubrir que algo es verdad conlleva compromiso, pues uno sabe que no puede doblegar la verdad a los propios intereses ${ }^{36}$. Pero cuando se trata de la relación de la verdad con la humildad, más que aludir a cualquier verdad, se está atendiendo a la verdad que uno es, es decir, al sentido personal, el cual no se puede conocer sin vinculación divina, lo cual comporta por fuerza humildad, porque es manifiesto que nadie es un invento de sus manos ni tiene el sentido personal completo en ellas; por tanto, solo puede estar por entero en manos del inventor de cada quién como persona distinta que es y está llamada a ser. Pero, por encima del concoer, «la humildad tiene que ver más con otra cosa, con el amor» ${ }^{37}$ personal. Tal amar no es ningún querer de la voluntad, pues esta potencia es de la esencia del hombre y sus quereres se inclinan hacia los bienes de que carece, pero el amar personal es del acto de ser personal y no es carente, sino efusivo, desbordante. A la esencia humana pertenece la inteligencia, la voluntad y lo que la psicología moderna denomina el yo (que Polo hace equivaler a la sindéresis o el ápice del alma según la filosofía medieval), raíz y respaldo de esas dos potencias inmateriales; pero la persona no es el yo, porque es claro que conocemos nuestro yo, pero no menos obvio que no sabemos enteramente quienes somos. En suma, «la humildad tiene que ver también con el amor personal, el cual es superior al yo, que es la cima de la esencia humana: la sindéresis» ${ }^{38}$.

Este último modo de decir agustiniano ha sido secundado recientemente por Carlos Díaz: «el primer paso en la búsqueda de la verdad es la humildad. El segundo, la humildad. El tercero, la humildad». DÍAZ, C. 2002: Repensar las virtudes. Madrid: Ediciones Internacionales Universitarias, p. 217.

Según la tesis clásica sobre la humildad cabe suponer que los agudos errores contra la verdad que encontramos en la filosofía, sobre todo en su época moderna y contemporánea, delatan que quienes los han formulado no están exentos del vicio contrario a esta virtud. Al menos este era el parecer de Hildebrand: «Aprendió una profunda lección, esto es, la importancia de la humildad en la vida intelectual. Se convenció de que los errores filosóficos son causados a menudo por una postura intelectual orgullosa y arrogante». VON HILDEBRAND, A. 2001: Alma de león, Biografia de Dietrich von Hildebrand. Madrid: Palabra, p. 142.

36 «También la humildad es imprescindible para alcanzar la verdad. Esa estrecha vinculación es señalada por Teresa de Jesús». Nietzsche como pensador de dualidades, ed. cit., p. 90. «La verdad es una propiedad que a uno le deja en suspenso por así decirlo, y que tiene una soberana autoridad racional que es objetiva y no subjetiva. Por lo tanto, la verdad no sojuzga, nunca es humillación». POLO, L. 2019: Ayudar a crecer. Cuestiones de filosofía de la educación, en Obras Completas, vol. XVIII. Pamplona: Eunsa, p. 259.

37 POLO, L., Conversaciones en Pamplona, 2-III-2015, pro-manuscripto, p. 1.

38 POLO, L., Epistemología, creación y divinidad, ed. cit., p. 301. En otro lugar escribe: «En el plano trascendental la humildad es inseparable del amor... Esto es especialmente aplicable al amor, una de cuyas bases es la humildad, precisamente por el gran aprecio hacia 
Además, «la humildad, por su referencia al conocer y al amar personal humano, contribuye a aunar estos dos trascendentales. Es, por tanto, un ingrediente intrínseco a la coexistencia trascendental ${ }^{39}$. Según Polo, la coexistencia libre personal es atemática; en cambio, el conocer y el amar personales son temáticos y su tema es Dios. Si la libertad personal es la actividad del espíritu que anima la búsqueda del tema del conocer personal y la aceptación de dicho tema por parte del amar personal, esto lo lleva a cabo la libertad personal gracias a su intrínseca humildad.

\section{LA REFERENCIA A DIOS DE LA HUMILDAD PERSONAL}

En las Sagradas Escrituras hay referencias a la humildad. Polo recoge algunas, como por ejemplo esa en la que se ve que:

Job llega al límite de su dolor y se queja, ante lo cual el Señor le responde: ¿¿sabes tú por dónde nace el sol?, que era igual que decirle: 'Tú no sabes nada, tú no me puedes pedir cuentas'. Job se humilló, lo reconoció: 'Tú eres superior, yo me humillo y haré penitencia por tamaña soberbia en saco y ceniza. ${ }^{40}$

Obviamente, en los textos sagrados también hay ejemplos de soberbia. Polo alude en este punto a la hipocresía de los fariseos: «fariseísmo es estar a cuentas con Dios, es pensar que ya no tenemos deudas. Es como decir: 'estoy ante Ti con regla de suficiencia' $\rangle^{41}$. También es claro que consideramos santos a aquellas personas que son más cercanas a Dios. De entre ellas Polo también trae a colación algún ejemplo: «qué diferente la actitud de Santa Catalina de Siena, a quien la humildad le hacía decir al Señor: 'nunca te he amado, no sé lo que es amarte', que es como decir 'estoy en deuda contigo, estoy en falta' $\rangle^{42}$. Entre los santos Polo resalta en especial la humildad de la Virgen ${ }^{43}$ y de $\mathrm{Cristo}^{44}$.

Pero la humildad no es solo un tema de la revelación o de la teología sobrenatural, sino netamente filosófico. En efecto, en el ámbito de la antropología trascendental cabe señalar que lo que más aleja al hombre del ser divino

la realidad que dualiza trascendentalmente a la persona humana». Nietzsche como pensador de dualidades, ed. cit., p. 90.

39 POLO, L., Nietzsche como pensador de dualidades, ed. cit., p. 90.

40 POLO, L., «Acción y contemplación». Conferencia pronunciada en la universidad de Piura (Perú) en agosto de 1990, pro-manuscripto, p. 5.

41 Ibid., p. 4.

42 Ibid., p. 4.

43 Cf. POLO, L., Epistemología, creación y divinidad, ed. cit., p. 248. Ese asunto lo reitera en «La persona humana como ser cognoscente», ed. cit., pp. 94 y 95.

44 Cf. Ibid., pp. 249, 271, 273, 295 y 296. 
(y de las personas creadas) es la soberbia ${ }^{45}$, la cual no es un vicio de la voluntad, sino del acto de ser personal. Si separa de las personas es, sencillamente, porque despersonaliza. En efecto, este defecto supone el decrecimiento del acto de ser persona ${ }^{46}$. En cambio, «el que procura humildemente descubrir y obedecer los designios de Dios crece a través de la lucha y, lejos de responder al mundo con una porción escasa de su ser, va entrando en escena con la sencillez intensa de la alegría» ${ }^{47}$.

Probablemente las actitudes de ateísmo, agnosticismo e indiferentismo religiosos tienen un gran componente de ignorancia sobre el tema real más elevado, Dios, pero esas actitudes seguramente tampoco están exentas de soberbia. Con todo, con la pérdida del ser divino, quien de él se aleja lo lleva a cabo a costa de ir perdiendo su sentido personal íntimo, porque «la vida de cada uno no tiene sentido más que dirigiéndose a Dios. Se trata de una respuesta que está globalmente acompañada de otra cosa que es la humildad» ${ }^{48}$. Obviamente, esa persona conservará muchos sentidos parciales, por ejemplo, el de su profesión, pero no tendrá un sentido global en su vida y, desde luego, estará falto de sentido personal.

En rigor, la humildad marca la dependencia radical de la persona humana respecto de Dios: «la humildad, en el sentido claro de dependencia humana, es el reconocimiento de que el hombre tiene una medida, que no se da el ser él mismo, sino que le viene dado, puesto que el hombre no es la plenitud del ser» ${ }^{49}$. Si la humildad dice referencia a Dios, dirá referencia libre, cognoscente y amante, puesto que -como se ha adelantado- está vinculada a los trascendentales personales; dirá sobre todo referencia amante al ser divino, puesto que el amar personal es el superior de dichos trascendentales: «el amor del hombre a Dios es algo que lleva consigo de una manera muy especial la humildad» ${ }^{50}$. Y esto, por lo indicado, porque:

El amor a Dios es siempre insuficiente. Esa insuficiencia no es de ninguna manera humillante, sino que tiene que ser acogida con humildad, sabiendo que uno es

45 «Cuando se descuida la humildad acontece el enfrentamiento con Dios». POLO, L., Antropología trascendental, vol. II, ed. cit., p. 509, nota 276.

46 «Lo peor para el ser personal es aislarse o ensoberbecerse, pues el egoísmo y la soberbia agostan el ser donal». POLO, L., Antropología trascendental, vol. I, ed. cit., p. 112.

47 POLO, L. 2015: La originalidad de la concepción cristiana de la existencia, en Obras Completas, Serie A, vol. XIII. Pamplona: Eunsa, p. 377.

48 POLO, L., Ayudar a crecer. Cuestiones de filosofía de la educación, ed. cit., p. 303.

49 POLO, L., «Con ciertas excepciones». Conversaciones con S. Bernal en Madrid a mediados de la década de 1970, pro manuscrito, p. 34.

50 POLO, L., «La Iglesia como sacramento y los sacramentos de la Iglesia». Conversaciones con S. Bernal en Madrid a mediados de la década de 1970, pro-manuscrito, p. 18. Esta sentencia poliana está en sintonía con la del místico castellano: «para enamorarse Dios del alma 
un pequeño amante, pero también dándose cuenta que eso de ser pequeño amante no significa una detención, sino un crecimiento: uno puede ser más amante ${ }^{51}$.

Para Polo el peor mal de la modernidad es el no querer reconocerse como criatura, en rigor, como hijo, puesto que «hijo es nombre personal. La libertad nativa es el nacer a la filiación en tanto que se nace como hijo» ${ }^{52}$. Por eso, «crecer en humildad es propio de abrirse a lo más grande, estar dispuesto a Dios» ${ }^{53}$. obviamente tal rechazo conlleva una visión deformada del resto de lo real $^{54}$.

\section{LA HUMILDAD DIVINA}

Comenzábamos diciendo que -según L. Polo- existe una realidad humana en la que no cabe soberbia: el conocer. Ahora, para finalizar -y siguiendo a este filósofo-, cabe decir que existe otra realidad que no puede ser sino humilde: el ser divino. Polo advierte esta prebenda divina en varios asuntos.

Por una parte, en el decreto creador, es decir, viendo a Dios de cara a fuera (ad extra), ya que «frente a la humildad del acto creador resalta penosamente la soberbia de los espíritus creados, pues éstos suelen despreciar a las otras criaturas mientras que Dios no desprecia a nadie» ${ }^{55}$. En efecto, el acto creador divino es desbordante, porque crea el ser, y lo lleva a cabo, por así decir, sin pasar factura, porque el ser dado es de la criatura, no de Dios.

Por otra parte, mirando el ser de Dios ad intra, pues «en Dios no hay distinción de niveles; por lo tanto, la voluntad de Dios tiene que ser amor de Dios. Por eso, a veces he pensado que la santidad de Dios es la humildad pura» ${ }^{56}$. Que no haya distinción de niveles en Dios equivale a sostener que en él no se da la distinción real jerárquica entre acto de ser y esencia. Tal distinción se da en lo creado, y el problema que pueden tener las criaturas espiri-

pone los ojos en la grandeza de la humildad». SAN JUAN DE LA CRUZ, Homilias sobre San Mateo, 15.

51 Ibid., p. 20.

52 POLO, L., Quién es el hombre, ed. cit., p. 179. En otro lugar indica: «Yo soy hijo; dependo de tal manera y tan radicalmente de quien me ha hecho hijo que no me puedo transformar en otra cosa de modo que según esa otra cosa yo sea. Yo tengo que aceptarme como hijo, pero aceptarme como hijo no es hacer nada, porque lo soy; aquí la aceptación no quita ni pone, sino que ontológicamente yo ya soy hijo; es lo que llamo libertad nativa». (2015): La esencia del hombre, en Obras Completas, Serie A, vol. XXIII, Pamplona: Eunsa, p. 291.

53 Polo, L., «Reseña sobre el libro Surco», cit., pro-manuscripto, p. 3, nota 7.

54 Sobre esto decía Marías que «la única verdadera humildad es aceptar la realidad». MARÍAS, J. 1973: Antropología metafisica. Madrid: Revista de Occidente, p. 13.

55 Polo, L., Epistemología, creación y divinidad, ed. cit., p. 109.

56 Polo, L., Conversaciones en Torreblanca (Colombia), 25-30-VI-1997, pro-manuscripto, p. 43. 
tuales, por ejemplo, los hombres, es albergar la pretensión de querer reconocer el sentido de su acto de ser personal en la esencia humana. Se trata de lo que Polo llama «pretensión de sí», la cual da lugar a la despersonalización, puesto que la esencia del hombre no es la persona, sino de ella. También la denomina «pretensión de identidad», pero solo Dios es idéntico ${ }^{57}$.

Juan Fernando Sellés Dauder es profesor Profesor Titular de la Universidad de Navarra y profesor visitante de varias universidades extranjeras.

Lineas de Investigación:

Antropología filosófica y Teoría del conocimiento

Publicaciones recientes:

2017: «Suarez and who denied the Agent Intellect in s. XVI», Scientia et Fides 5, pp. $117-140$.

2017: «The Active Intellect in Several Franciscan's Masters on XVIIth Century», Cauriensia. Revista Anual de Ciencias Eclesiásticas et Fides 12, pp. 661-684.

Correo electrónico: abastidas.1@alumni.unav.es

57 En rigor, «pretender la intimidad como identidad... equivale a hacer caso a las palabras bíblicas 'seréis como dioses'». POLO, L. 2017: Persona y libertad, en Obras Completas, vol. XIX, Serie A. Pamplona: Eunsa, p. 69. 